\title{
SAVE THE OBESE MAN (SOS FOR HOMO OBESUS)
}

\section{Effective adipopolitics and adipoeconomics are urgently required. An appeal to politicians A Symposium for our times:}

\section{Echo from the Fifth International Symposium on Adipobiology and Adipopharmacology (ISAA), 1-4 May 2019, Merida, Yucatan, Mexico}

\author{
Marcia Hiriart ${ }^{1}$, Marco Fiore ${ }^{2}$ and George Chaldakov ${ }^{3}$ \\ 'Institute of Cell Physiology, Universidad Nacional Autonoma de Mexico (UNAM), Mexico City, Mexico, \\ ${ }^{2}$ Institute of Biochemistry and Cell Biology, Section of Neurobiology, National Research Council (CNR), Rome, Italy, \\ and ${ }^{3}$ Department of Anatomy and Cell Biology, Medical University, Varna, Bulgaria
}

When someone declared that life is an evil,

Diogenes said: Not life itself, but living obese.

Adiobiology (adiposcience) is a research field dealing with molecules, structures and functions of adipose tissue in health and disease. Adipopharmacology aims at finding obesity drugs and related cardiovascular, neurodegenerative and other diseases.

The Bulgarian Society for Cell Biology organized the first, second and third International Symposium on Adipobiology and Adipopharmacology (ISAA) respectively in 2007 and 2009 in Varna, Bulgaria and 2012 in Burgas, Bulgaria. The fourth ISAA was organized by the Romanian Medical Academy in Bucharest, Romania in 2015.

The Fifth ISAA was held on 1-4 May 2019 in Merida, Yucatan, Mexico. The symposium was organized by the Universidad Nacional Autonoma de Mexico (UNAM) and the Universidad Autonoma de Yucatan (UADY) in collaboration with the Bulgarian Society of Cell Biology.

In vivo veritas - scientists from Mexico, Italy, Bulgaria, Canada, India, Poland, the United States and Brazil, we gathered again to share new results and hypotheses. Chairwoman of the Fifth ISAA was Professor Marcia Hirriart from the Department of Cognitive Neuroscience, Institute of Cellular Physiology of UNAM, Chairman of the ISAA was George Chaldakov from the Department of Anatomy and Cell Biology, Medical University, Varna. Scientists with a very high BMI (brain mass index) presented 24 state-of-thescience (SOS) lectures and 37 posters. In the title of the Mexican „echo, “ the classic SOS (save our souls) becomes "save the obese man“. The Merida Symposium was a world-class scientific event (Photographs 1, 2 and 10 Links for YouTube). 


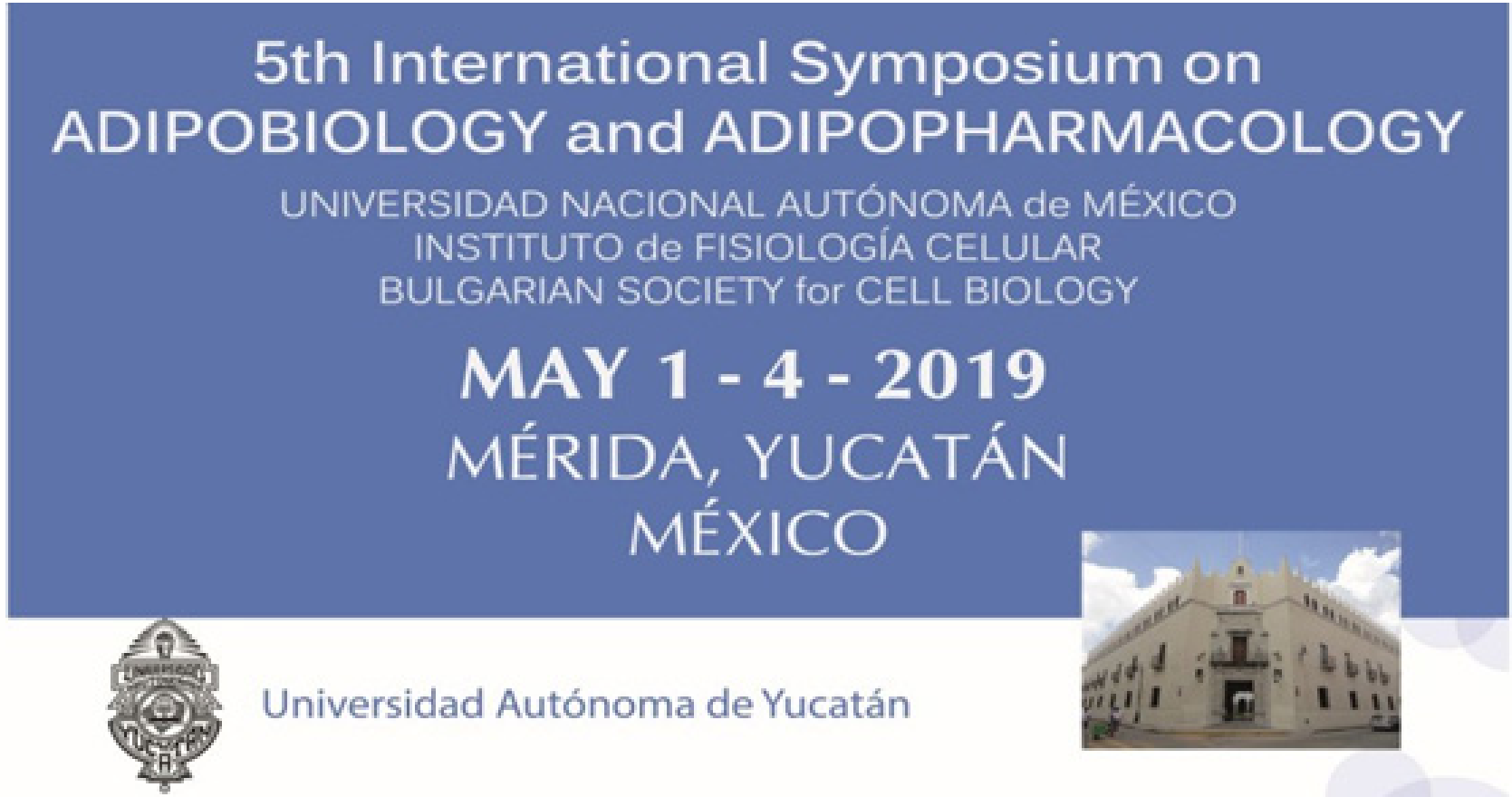

\section{THEMES:}

- Cellular and molecular biology of brown, beige and white adipocytes

- Adipose-targeted Pharmacology

- Adipose tissue development

- Hormonal and nervous control of the adipose tissue

- Overweight, obesity, type 2 diabetes, cardiometabolic and other diseases

Abstracts submission: maximum 300 words, ends on March 25th

FOR MORE INFORMATION:

bgscb2019mx@gmail.com
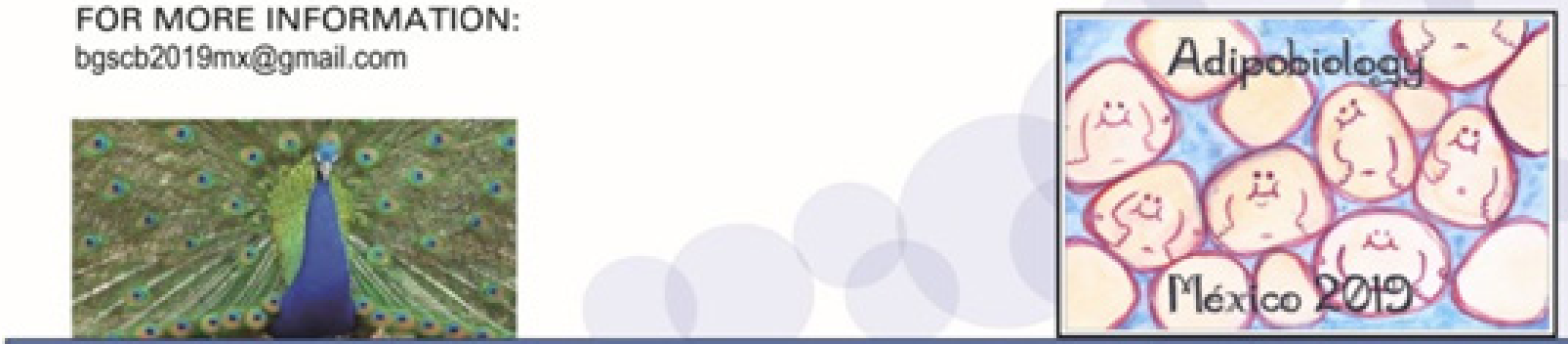

http://www.5isaa.org
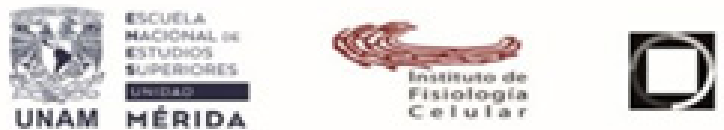

Adipobiology

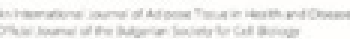

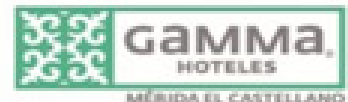




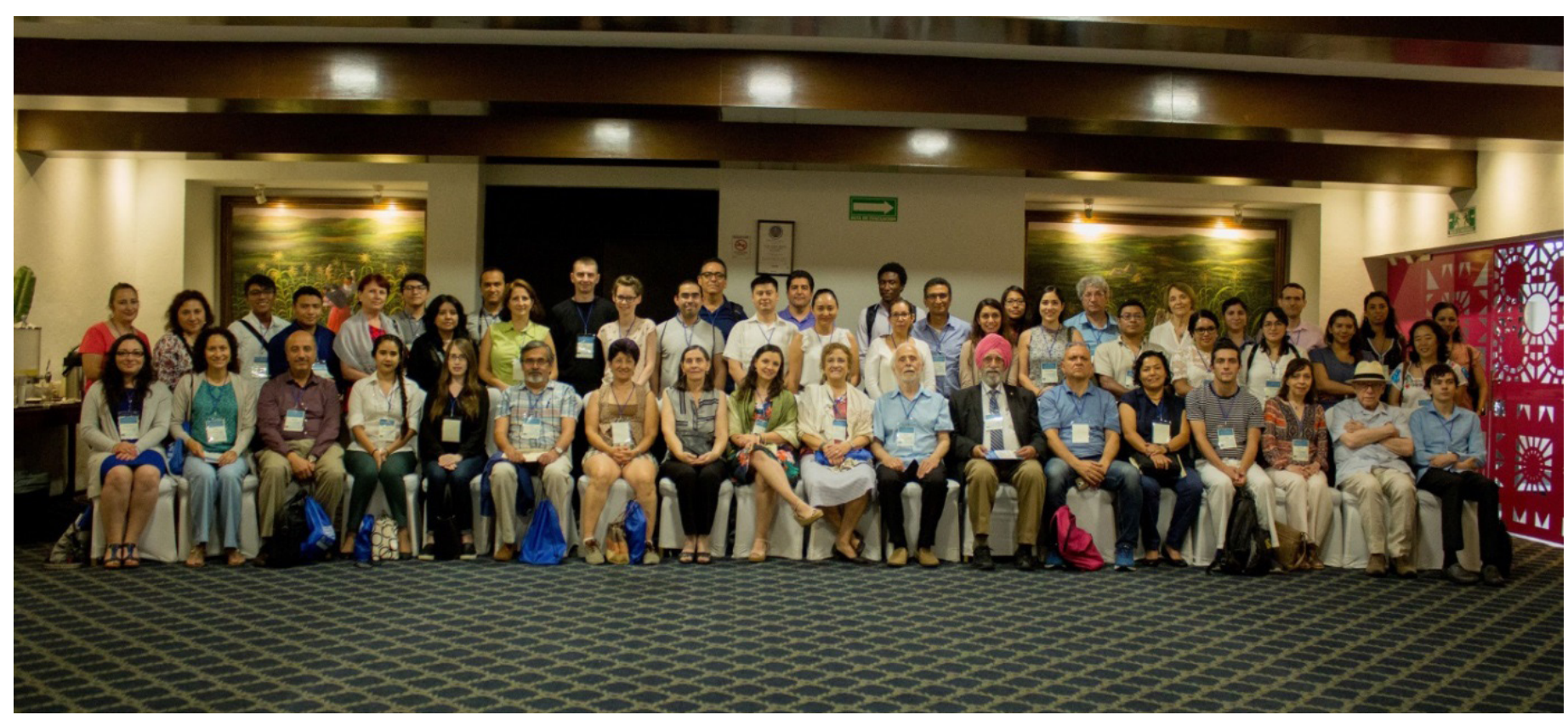

The participants at the Symposium in Mexico.

Some footage from the Merida Symposium documented on YouTube:

5th ISAA Opening Ceremony Marcia Hiriart

https://www.youtube.com/watch?v=rXfIJE4IyF0

5th ISAA Opening Ceremony George Chaldakov

https://www.youtube.com/watch?v=g_jYmdsc4FQ

5th ISAA Opening Ceremony Nikifor Chaldakov

https://www.youtube.com/watch?v=BshPVzlPZ4E

5th ISAA Declaration of BHF Closing Ceremony

https://www.youtube.com/watch?v=pULf_hmzMlQ

Merida (Mérida) is the capital of Yucatan, the Mayan country. A million-dollar town inhabited by friendly people, mostly one-two-stored houses and many palm trees. The houses are painted in different colors from the palette of Diego Rivera - one of the „Big Three“ Mexican artists of the last century. Among them are the palm trees - the perfectly upright geometry of their bodies is raised to tens of meters from the ground. To the north of Merida is the ancient city of Chichen Itza (the Iza tribe in the Mayan language) - the pyramids built by the Mayans - a meeting of architecture and astronomy, some of the wonders of the world.

Merida is about $30 \mathrm{~km}$ from the Gulf of Mexico - you rise on the beach in Progress and see Miami, Florida. "The sea is everywhere sea», as Hristo Fotev said. But here in Progress, the beach is accessible and free for everyone. Waiters from the sloping restaurant bring tables to the sand and kindly bring you the portions of fish, beers and tortilla (Mexican cakes). There are Mexican gulls and gulls flying and landing, waiting patiently for their meals.

\section{Four apples that changed the world:}

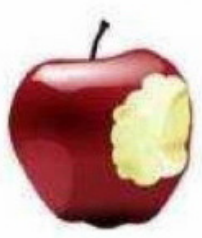

of Eve

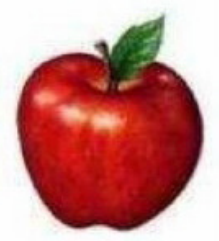

of Isaac Newton

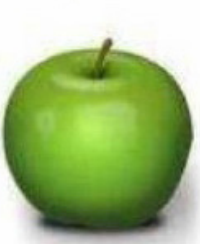

of Beatles

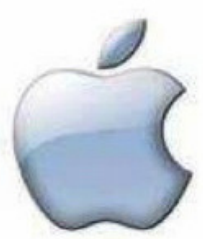

of Steve Jobs
Figure 1.

In the last 20-25 years adyobiology is one of the most intensely developing biomedical sciences. It has been found that fat tissue is the most productive endocrine gland (gland with internal secretion) of the human body; the cells of this tissue produce more than 500 hormones - proteins, collectively called adipokins. They are multifunctional molecules - besides control of body weight, they also influence other biological processes inflammation, immunity, reproduction, memory. Accordingly, researchers study adipose tissue diseases - cardiovascular diseases (atherosclerosis, hypertension, obesity, type 2 diabetes, metabolic syndrome) and their complications - heart attacks and strokes. According to the World Health Organization, around 19 
Lean adipose tissue

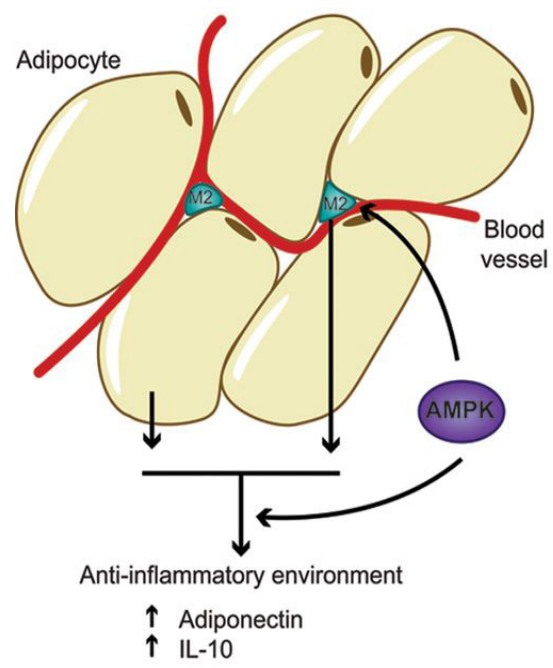

Obese dysfunctional adipose tissue

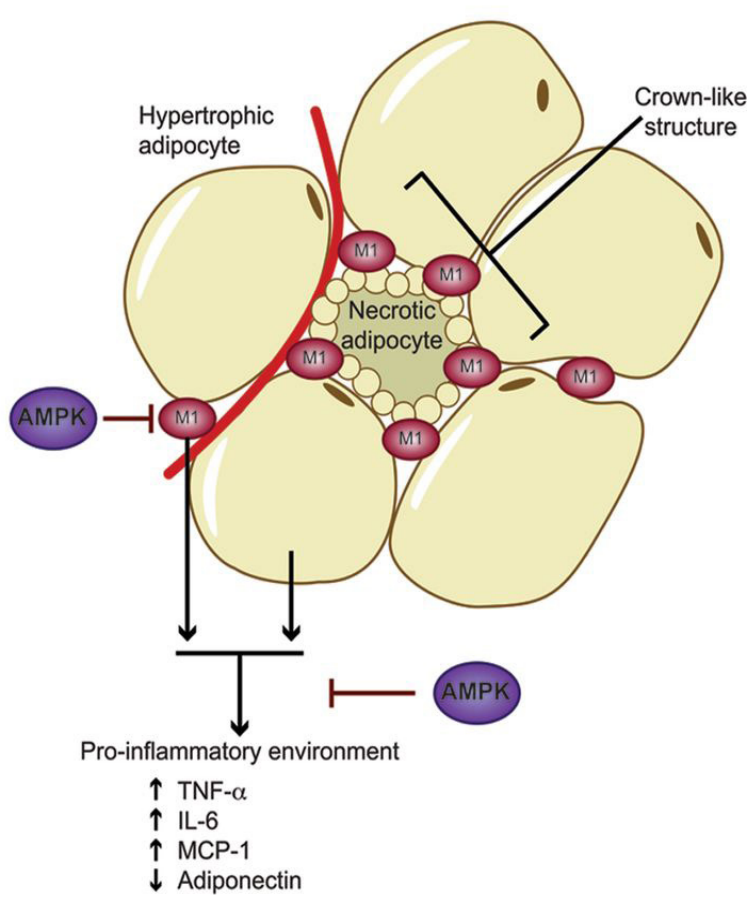

Figure 2. The fifth apple that changed the world is "the big adipocyte". Schematic presentation of adipose tissue. The yellow formations are fat cells (adipocytes) - left, „elegant" adipocytes, right - "fat" adipocytes, the ones that make Homo obesus.

From: Thomas Tsiloulis, Matthew J. Watt, Molecular and cellular regulation of adaptation to exercise. In: Progress in Molecular Biology and Translational Science. 2015. million people worldwide die of these diseases annually. There are over 1 billion overweight people in the world, about 500 million of whom are obese. About 700 million people live in Europe, about 150 million of whom are obese. It is particularly worrying that the epidemic also affects children.

Centuries ago, Diogen (412-323 BC) said, „I am a citizen of the world." Since the 1980s, Homo obesus (the obese person) has repeated these words of the ancient Greek philosopher. One of the routine indicators of obesity is the body mass index (BMI) - the weight value in kilograms divided by the height in meters per square $(\mathrm{kg} / \mathrm{m} 2)$ - when the result is over 30 , the person is obese (Tabl. 1-3).

The socially weak and uneducated in Bulgaria and the politicians are the biggest fatheads in the world. In the United States, for example, the average BMI of Americans is about 28. So, US senators and journalists are increasingly discussing: „These are fat times in politics, “”Fat tax, “” „How obesity threatens America's future? „" "Is Al Gore too fat? ”

In Mexico and Bulgaria, no one has ever asked „How does obesity reflect on the future of Mexico and Bulgaria?" Both Mexico and Bulgaria have a prestigious adiobiology and adipopharmacology, but there is no effective adipopolitics and adipoeconomics. There are politicians who do not pay attention to Homo obesus and to children with obesity, diabetes and hypertension. Neither scientists working in cardiometabolic adipobiology. And all of this - both in Mexico and Bulgaria
Table 1. Human weight and body mass index (BMI) values

Weight BMI (kg / m2)

Underweight $16-18$

Normal $18-25$

Overweight 25 - 30

Average Obese 30-35

Severe Obese 35-40

Very heavy obese over 40

Table 2. Localization of human adipose tissue: variants +

TOFI ${ }^{* *}$ thin outside, fat inside

TOTI ***** thin outside, thin inside

FOTI* fat outside, fat inside

FOTI*** fat outside, thin inside

+ The number of stars means quality of health. Therefore, be a TOTI!

Table 3. Diseases associated with dysfunction of adipose tissue

Obesity, Type 2 Diabetes, Metabolic Syndrome, Atherosclerosis, Hypertension, Alzheimer's disease (Type 3 diabetes?),

Polycysticovary syndrome, Non-alcoholic fatty liver, Obstructive sleep apnea, Crohn's disease, Thyroid-associated ophthalmopathy, Rheumatoid arthritis, Asthma, Breast cancer, Prostate cancer, Colorectal cancer, Lipodystrophy ... 
- in the face of more than anxious statistics - Mexico are the first in the children and the second, after the US, with adults in America, whereas Bulgaria, with about one and a half million obese children and adults, is at the forefront of Europe.

From a financial point of view, these are hundreds of billions of euros and pesos per year for healing, retiring and disabling the people affected by „obese“ diseases (see Table 3).

Major non-communicable diseases, including cardiovascular diseases, are particularly damaging not only to human health but also to the economy in all countries of the world - more than 2 million people die in Europe annually from the complications of these diseases and more than 192 billion euros are spent on them. Accordingly, primary and secondary prevention can improve people's health and save billions of euros/dollars to invest in sports for health and to improve the quality of education and quality of life both of Mexicans and Bulgarians!

However, solving these problems can not be achieved without the political will of a long-term preventative strategy of obesity and related diseases. And without science-based medicine.

Our politicians do not hear what the scientists are alarming: „We know how it works, we know how much it costs and we know that all countries are in cardiometabolic risk. We have an Action Plan on how to protect millions of people from premature death and how to improve the quality of life of millions of people" (www.who.int/nmh/Actionplan-PC-NCD-2008.pdf).

\section{Cardiovascular disease: a costly burden for America} Projections through 2035 (data according the American Heart Association and the American Stroke Association)

Cardiovascular diseases (CVD) have become USA's costliest chronic disease. In years past, a heart attack or stroke almost certainly resulted in death. But advances in biomedical research, improved emergency response systems and treatment and prevention efforts have helped Americans fight back. Between 2000 and 2011, researchers found the national heart-related mortality rate declined at an average of 3.7 percent per year, while stroke mortality declined at 4.5 percent per year. But in the past few years this remarkable progress has stalled.

The burden of cardiovascular disease is now growing faster than our ability to combat it due to the obesity epidemic, poor diet, high blood pressure and a dramatic rise in Type 2 diabetes - all major risk factors for heart disease and stroke. In a frightening reversal, the overall decline in CVD mortality rates have flattened to less than 1 percent per year since 2011, and rates have even worsened for our most at-risk populations. In 2015, the death rate from heart disease actually increased by 1 percent for the first time since 1969, according to the Centers for Disease Control and Prevention's (CDC) National Center for Health Statistics.
In $2015,41.5$ percent ( 102.7 million) of the USA population had at least one cardiovascular disease:

$\begin{array}{ll}\text { High Blood Pressure } & 96.1 \text { million } \\ \text { Coronary Heart Disease } & 16.8 \text { million } \\ \text { Stroke } & 7.5 \text { million } \\ \text { Congestive Heart Failure } & 5.8 \text { million } \\ \text { Atrial Fibrillation } & 5.2 \text { million }\end{array}$

In 2035, the number of Americans with CVD is projected to rise to $\mathbf{1 3 1 . 2}$ million - 45 percent of the total USA population. This means additional increases of medical costs.

$\begin{array}{ll}\text { High Blood Pressure } & 27.1 \text { million } \\ \text { Coronary Heart Disease } & 7.2 \text { million } \\ \text { Stroke } & 3.7 \text { million } \\ \text { Congestive Heart Failure } & 3.0 \text { million } \\ \text { Atrial Fibrillation } & 2.0 \text { million }\end{array}$

Projections - CVD Medical Costs Through 2035

\begin{tabular}{|l|l|l|}
\hline Current & $\mathbf{2 0 3 5}$ & \\
\hline Hyper-tension & $\$ 68$ billion & \$154 billion \\
\hline CHD & $\$ 89$ billion & \$215 billion \\
\hline CHF & $\$ 18$ billion & \$45 billion \\
\hline Stroke & $\$ 37$ billion & \$94 billion \\
\hline AFib & $\$ 24$ billion & \$5 billion \\
\hline Other & $\$ 83$ billion & \$187 billion \\
\hline Total medical costs & $\mathbf{\$ 3 1 8}$ billion & $\mathbf{\$ 7 4 9}$ billion \\
\hline
\end{tabular}

Hopefully, SOS for Homo obesus will at long last be hearn by Mexican and Bulgarian politicians and they will cooperate financially and organizationally with biomedical scientists, medical doctors and school and university teachers.

Because "the life, health and education is the truth".

Because obesity negatively affects the present and the future of our countries. And of the world - that is termed globesity.

\section{Coda}

„Imagine Mexico and Bulgaria without obesity“ - a (still) utopian lyric about the health of all the Mexicans, Italians and Bulgarians. 